\title{
Teaching and researching computer-assisted language learning'
}

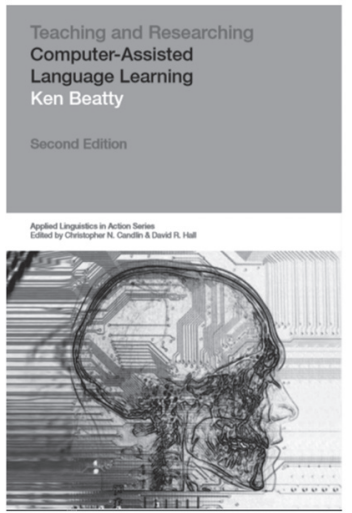

Beatty, K. (20|0). Teaching and researching computerassisted language learning. London: Pearson Education Limited.

Reviewed by:

Saieed Moslemi Nezhad Arani

TEFL Ph.D. Candidate

Imam Khomeini International University, Qazvin, Iran

7 he prominence of technology has always been booming since computers generated new lanes for human to make use of high-tech for many different purposes. Utilizing computers for learning goals, among many, is one of the main concerns followed by educational issues in teaching and learning, especially, of a new language. Computer-assisted language learning (CALL) is known as a

1 Received: June 8th 2018/ Accepted: Novemember 17th 2018

2 saieed91@yahoo.com 
branch of language studies which focuses on teaching and learning of a new language through applications of computers in language learning contexts. Many books, articles, reviews, etc. being published regularly consider one or some issues related to the CALL. To this, researchers have tried to introduce or evaluate particular application of CALL in the mentioned field.

Cameron (1988, p. 15) reasons that "The fact that there are so many different types of CALL programs in existence illustrates the futility of attempting to define a single set of program principles or structures to fit all situations." Other subordinate technologies interconnected to the computerized exemplar have influenced the teaching practice. For example, information communication technology (ICT) "has been integrated within the overall design of the methodology used in the language learning process as a key factor." (Zhang, 2012, p. 8). Other similar well-intentioned works can be referred to (Holland \& Fisher, 2008; Donaldson \& Haggstrom, 2006; Thomas, Reinders, \& Warschauer, 2013) which consider discussions of series of actions taken as regards the CALL subject.

Beatty's Teaching and researching in computer-assisted language learning (2010) is considered as one of the most comprehensive books on defining and reorganizing concept of CALL into the language education. The following is a review based on Beatty's book, which is highly recommended for a thorough reading and anlisis.

The book includes four sections and 10 chapters, together with appendices and a research sample chapter. The author follows a perfect build-up move towards the CALL question through chapters. He starts from introducing the early concepts of CALL to the most up-to-date ones. In chapter 1 , section 1 named Key Concepts, Beatty tries to give a clear definition of CALL through presenting the key notion that still there are other terms corresponding to the subject, however, with the same connotation. Moreover, he emphasizes on the technology-driven nature of CALL in which improvements in computer technology, from the hardware to the software, have played roles as tools in pedagogy and research. He conceptualizes that CALL not only is part of the classroom teaching, it can also be applied complementary to all classroom teaching and learning activities. This distinguishing feature of CALL has proved its advantages to the teachers in a way they profit its lead in their teaching, assessments, and enhancing programs for students.

Through the second chapter, a brief history of CALL is given. The author portrays CALL history from the early 1950 s to the contemporary times. He lists the hardware and software developments and argues 
how the new generation of desktop computers helped teacher-led research. In the early ages, much software developed based on the behavioristic view of language teaching and learning. However, later on, developments in Web technologies have devoted new friendly-use generation of learning activities to the language learning classrooms and contexts.

Chapter 3 with a focus on multimedia introduces hypertext, hypermedia, and multimedia as distinctive features of the computers in presenting things differently and effectively in comparison to traditional or classical teaching and learning materials. However, gradually, because of the universal growth and use of multimedia in learning and online application, research on finding improved and operative impact multimedia may have on learning replaced itself with latest technical innovations towards learning. For example, "the creation of virtual worlds using avatars to represent people in MOO-like virtual object situations (see The Lost Moo Library at http://www.hayseed.net/MOO) continues to develop in sophistication and in the opportunities they present for interaction." (Beatty, 2010, p. 56).

Beatty in chapter 4 of his book describes eight CALL applications such as word processing, games, literature, corpus linguistics, computermediated communication, WWW resources, adopting materials for CALL, and personal digital assistants (PDAs) and mobile telephones. The key point that he argues in this chapter is the various ways of using CALL. The author, smartly, highlights that the successful presentation of such applications directly depends on the amount of work teachers and learners allocate to them before language learning begins. That is, as Beatty argues, if teacher and learners do not identify or apprehend the application, or it is too complex for them, then irrespective of the delightful advantages of technology in teaching and learning, it will be useless and a waste of time.

Chapter 5, entering section 2 titled "the place of CALL in research and teaching", second language acquisition and models of instruction are discussed by introducing theories of language learning supporting CALL such as behaviorism, and constructivism. The author defines the programmed instruction and mastery learning following the theories of learning. Also, he describes the benefits and deficits of each in view of CALL software programs and Second-Language Acquisition (SLA). Beatty elucidates that binary logic feature of computers best fits the behavioristic models of learning. However, he puts forward that constructivism accompanied by schema theory as a specific principle, contrary to the behavioristic view, simplifies collaboration and negotiation of meaning in CALL models. 
In chapter 6 , the author pays special attention to the collaboration and negotiation of meaning in CALL. The chapter gives a definition on collaboration with a focus on other researchers' definitions of the term. To this end, the author exemplifies collaborative issues recommended by others for enhancing awareness and developing skills, attaining pedagogical objectives, improving literacy, and supporting language acquisition. In addition, he compares the concept of collaboration with other similar perceptions such as cooperative and teamwork to reach a clear and typical definition for collaboration concept, and finally consents himself with the definition from Dillenbourgh et al. (1995, cited in Beatty, 2010, p. 141), "a coordinated, synchronous activity that is the result of a continued attempt to construct and maintain a shared conception of a problem." However, his definition brings up the constructivist model of learning, contrary to the expectation that behaviouristic model of learning that is in the same collaborative approach. According to the author, collaboration at the computer level can be supported through discourse. Such discourse can illustrate the strategies learners use to report and elude a range of challenges to collaboration.

Beatty (2010) discusses defining a model for CALL in chapter 7 in his book. At the beginning of the chapter, the author clarifies the nature of the concept of model in which it refers to the representative of all things possible in a classroom. Accordingly, there are also some other limitations towards defining a CALL model for a classroom since some factors such as lack of money resources, needs for proficient expertise, and absence of enough equipment affect a model for CALL classroom. Despite the fact that user-friendly applications are accessible online, such applications cannot be suitable in proposing a complete languagelearning program. However, one can not ignore their complementary role in helping the teachers in classroom activities. Thus, the author magnifies a gap toward a need for a comprehensive CALL model to help both material developers and evaluators in providing a CALL model of language-teaching which comprises all essential aspects in a way that the teacher finds himself simply as a facilitator.

In the rest of chapter 7 , Beatty focuses on the scope of variables involved in learning and teaching proposes (Dunkin and Biddle's, 1974) model for CALL. He also clarifies that presage variables, context variables and process variables in a CALL model are different, but he believes that the so-called model can best match a CALL course to be a comprehensive model of language-teaching. To this, several views of CALL are discussed with an emphasis on the activities used in a model of locus of control at the computer. According to this model, activities 
on the part of the learner in a CALL model can range from little or no control to complete control. That is a move from a behaviouristic approach gradually to a constructivist approach. At the end of the chapter, the author introduces the idea of the virtual classroom on the basis of Dunkin and Biddle's model, and he claims that designing a CALL model engendered from the mentioned model not only can provide a comprehensive CALL model, also it can act as a kind of virtual teacher. However, Beatty takes as granted that reworking Dunkin and Biddle's model does not mean a perfect jump, and precautions should be taken since still there are some variables in CALL that Dunkin and Biddle's model never supports.

Chapter 8 is dedicated to the discussion of the theoretical and pedagogical concerns of CALL. This chapter begins with the argument of challenging areas in CALL in which research and studies need to be conducted in order to clarify the practical implications. One of the thought-provoking areas that seems has been one of the main considerations of author, among many others, is introduced as the complications of facing children using the WWW, proper education as to the nature of problems, and appropriate actions needed to be taken against them.

Chapter 9 of the Beatty's book builds up on the previous chapter and mostly discusses the current research interests and trends in CALL. The author believes that a classroom teacher should be a researcher at the same time. That is, a teacher is not only an instructor, also s/ he should analyze the class and students' needs towards successful course objectives and become ready for conducting any studies to find necessary solutions. Learners are also recommended to be much more involved in the research process, contributing perspectives and commenting on findings. The chapter proposes different kinds of research and methodology that can be applicable in a CALL course model. However, at the closing part of the chapter, action research is highly recommended for teachers in the classroom.

The last chapter, chapter 10 , is dedicated to the discussions and guidelines in conducting a research in CALL-based classrooms. The author refers to the different types of studies such as pilot study, corpus linguistics, error analysis, case study, survey, and ethnographic approach that match to the area, and he advocates for the advantages of such studies and their findings in developing, implementing, and evaluating a CALL model. However, for a suitable CALL model, one should consider the basic questions of what is needed for a comprehensive CALL model that can replace the teacher and even the learner's peers 
for a successful language-teaching context. However, steps have not still been taken toward designing and assembling a comprehensive and complete CALL software program for a language to be taught regardless of time and place. At the end, the author recommends that in order to get much closer to the desired complete model, one may consider the things that teachers do best and the things that computers are able to perform best.

To sum, the discussed book gives the impression that for designing and implementing a CALL-based course not only the proposed models of teaching have the applicability to the language teaching field, also it offers some of the main and primary implementation of CALL into the language teaching classrooms in a way that one may think of them as useful hints to provide supplementary and modern innovative ideas for CALL practices in language teaching and learning. Since it associates the compatibility of CALL-based models with second-language acquisition models of instruction analytically, and due to the fact that it emphasizes on the role of collaboration and negotiation of meaning in discussing the CALL-based models, it is highly recommended as a good resource in providing models of CALL for language teaching courses, especially for children CALL-based language teaching and learning courses which have not been studied deeply. 


\section{References}

Beatty, K. (2010). Teaching and researching computer-assisted language learning. London: Pearson Education Limited.

Cameron, K. (1988 ). Computer-assisted language learning: Program structure and principles. Oxford: Intellect Books.

Donaldson, R. P., \& Haggstrom, M. A. (2006). Changing language education through CALL. New York: Routledge.

Holland, V. M., \& Fisher, F. P. (2008). The path of speech technologies in computer assisted language learning: From research toward practice. New York: Routledge.

Thomas, M., Reinders, H., \& Warschauer, M. (2013). Contemporary computer-assisted language learning. London: Bloomsbury Academic.

Zhang, F. (2012). Computer-enhanced and mobile-sssisted language learning: Emerging issues and trends. Canberra: Information Science Reference. 


\section{Author}

*Saieed Moslemi Nezhad Arani is a TEFL Ph.D. candidate at Imam Khomeini International University, Qazvin, Iran. He received a bachelor's degree in English Language Translation Studies from Aran \& Bidgol Payame Noor University, and a TEFL master's degree from Sistan and Baluchistan University in Zahedan, Iran. He has published numbers of articles in TEFL studies, and participated in several conferences with the main interest towards discourse analysis, corpus analysis, and computer assisted language learning. 